\title{
Haemodynamic and electrocardiographic effects of frusemide during supine exercise in patients with angina pectoris
}

\author{
W NECHWATAL, * E KÖNIG, J ISBARY, H GREDING, M STAUCH \\ From the Second Medical Department, Krankenhaus München-Schwabing, Munich, and the \\ Division of Cardiology, University of Ulm, Ulm, West Germany
}

SUMMARY The influence of frusemide on haemodynamic, electrocardiographic, and symptomatic response to exercise was studied in 19 patients with documented coronary artery disease. During the control exercise period all patients experienced angina and showed ST segment depression, accompanied by raised pulmonary artery wedge pressures (PWP). In 12 of these patients $40 \mathrm{mg}$ frusemide was administered intravenously and in the other seven patients $40 \mathrm{mg}$ frusemide was given orally. After significant diuresis $(>400 \mathrm{ml})$, the exercise test was repeated. Data were collected at the same exercise work load and duration as had been achieved before frusemide.

Both in the intravenous and oral group there was a reduction in cardiac output at rest and a less obvious reduction during exercise. The PWP during exercise after intravenous frusemide decreased from 32.9 to $11.8 \mathrm{mmHg}$ and after oral frusemide from 30.7 to $15.7 \mathrm{mmHg}$. During the control period there was evidence of mitral regurgitation in seven of the patients during angina, as shown by high amplitude $\mathrm{v}$ waves in the PWP recordings. These alterations disappeared completely after the administration of frusemide. Ischaemic ST depression improved in 15 of 19 patients after frusemide $(0.21$ vs $0.09 \mathrm{mV})$. Furthermore, there was a reduction of complete suppression of anginal pain in 18 of 19 patients. Ten patients were capable of continuing exercise for a further period of time at the same work load.

These data, demonstrating the antianginal properties of frusemide, may be explained by the reduction in ventricular volumes and pressures, resulting in a decrease in myocardial wall stress and oxygen demand. The effects may be the result of both the diuretic action of frusemide and its venodilator capacity.

Frusemide has been extensively used in the treatment of heart failure and its effects on cardiovascular dynamics in failure are well established. ${ }^{1-3}$ Clinical relief of symptoms of pulmonary congestion frequently precedes any demonstrable diuretic effect, suggesting that extrarenal factors may also be involved. ${ }^{4}$ More recent studies on the extrarenal action of frusemide showed an increase of venous capacitance as an early haemodynamic effect of the drug. ${ }^{6}$

Little is known, however, about the effects of diuretics in patients with left ventricular dysfunction secondary to myocardial ischaemia. Dikshit et al. ${ }^{\text {? }}$

*Present address: Division of Cardiology, University of Ulm, Steinhövelstrasse 9, 7900 Ulm, West Germany.

Received for publication 11 October 1979 suggested that similar haemodynamic changes may occur after frusemide and glyceryl trinitrate in patients with acute myocardial infarction. The clinical observation of Wilkins, ${ }^{8}$ and Hollander et al. ${ }^{9}$ that administration of diuretic agents may be associated with amelioration of anginal pain, have prompted us to study the possible role of frusemide in patients with typical exercise-induced angina pectoris. Spontaneous changes in the course of coronary artery disease may obscure the effects of any drug intervention after sustained oral treatment in patients with angina pectoris. For this reason, a single dose was used to assess the effectiveness of intravenous and oral frusemide in patients with angina pectoris and documented coronary artery disease not in clinical heart failure. Because 
of the subjective nature of antianginal response alone, emphasis is placed on the influence of the drug on haemodynamic variables and on ischaemic ST depression.

\section{Subjects and methods}

Nineteen patients, aged 42 to 61 years (average 52 years), with coronary artery disease and stable exercise-induced angina pectoris were studied. All patients had either a history of clearly documented myocardial infarction (eight subjects) and/or angiographic proof of more than 70 per cent narrowing in at least one major coronary artery. None had received diuretic drugs, antihypertensive agents, nitrates, or beta blocking agents within 48 hours before examination. The history of anginal pain ranged from six months to eight years and was induced by physical exercise in all patients. None had clinical or radiological evidence of cardiac enlargement or failure, valvular heart disease, or arrhythmias. Informed consent was obtained from each patient.

Thirty minutes before the study period, all subjects exercised at a work load comparable to that of the following main exercise periods. This allowed us to observe the patients' response, the potential occurrence of rhythm disturbances, and also to attenuate the influence of previous exercise per se on the haemodynamics during the study period.

Right heart catheterisation was performed without premedication using Swan-Ganz flow-directed catheters for the simultaneous determination of right atrial pressure, pulmonary artery pressure, or pulmonary artery wedge pressure. Pulmonary artery wedge pressure was considered as a reasonable approximation to left ventricular filling pressure. ${ }^{10}$ Cardiac output was determined in triplicate by means of the thermal dilution technique with the same catheter equipment. ${ }^{11}{ }^{12}$ Systemic blood pressure was recorded either by introducing polyethylene cannulae percutaneously into a brachial artery (10 cases) or by a sphygmomanometer (nine cases). All intravascular pressures were determined with a Statham strain gauge from a zero reference level $6 \mathrm{~cm}$ below the angle of Louis and averaged over 10 heart cycles. The pressures and the praecordial electrocardiographic leads V4 to V6 were monitored on an oscilloscope throughout the study and recorded simultaneously at a paper speed of $50 \mathrm{~mm} / \mathrm{s}$ on a multichannel recorder. ST segment depression was measured during the maximal horizontal or downsloping displacement below the level of the PR interval.

Following recordings of the resting values the patients performed supine leg exercise on a bicycle ergometer at a constant, individualised work load previously determined to evoke angina consistently within three to six minutes. The pressure recordings and electrocardiograms were repeated during exercise at one minute intervals and during the exercise angina episode. The exercise value of cardiac output was measured during the final minute of exercise, when the patients indicated the presence of definite chest pain. The patients were familiar with describing the degree of chest pain as "mild", "moderate", or "severe" from previous examinations.

After completion of the control study period $40 \mathrm{mg}$ frusemide were given intravenously to 12 patients and $40 \mathrm{mg}$ oral frusemide to seven patients. Within 25 minutes after intravenous administration of the drug, all patients in this group micturated spontaneously more than $400 \mathrm{ml}$ urine. At this time each patient was restudied in an identical manner. In the oral group the post-frusemide study was performed 50 to 90 minutes (average 61 minutes) after administration, depending on the time of spontaneous micturition of more than $400 \mathrm{ml}$ urine. Data were collected at the same exercise work load and duration as during the control study period. Those patients who were free of complaints and capable of continuing exercise were asked to do so at the same level of work load for a further period of time. Pressure values, as in the pre-frusemide study, were obtained at one minute intervals during exercise. Exercise cardiac output in the postfrusemide study was measured at the same time as during exercise before frusemide, irrespective of the presence or absence of angina pectoris.

Statistical analysis of the data was carried out using paired Student's t test.

\section{Results}

\section{(A) HAEMODYNAMIC STUDIES}

The haemodynamic response to intravenous and oral frusemide is presented in Fig. 1 to 3 . Left ventricular filling pressure, as reflected by the mean pulmonary artery wedge pressure (PWP), decreased slightly at rest. Before frusemide, a precipitous increase in PWP was observed during exercise in all but one patient. After frusemide, at the same exercise duration as before the drug, there was a striking decrease of exercise PWP by 64 per cent in the intravenous group $(32.9 \pm 11.1 \mathrm{mmHg}$ vs. $11.8 \pm 5.5 \mathrm{mmHg}, \mathrm{p}<0.001)$ and by 49 per cent in the oral group $(30.7 \pm 5.4 \mathrm{mmHg}$ vs. $15 \cdot 7 \pm 9 \cdot 1$ $\mathrm{mmHg}, \mathrm{p}<0.01$ ). Values of PWP in patients receiving intravenous frusemide are shown in detail in Fig. 3. Each of the 12 subjects showed a reduction in exercise PWP after frusemide. 

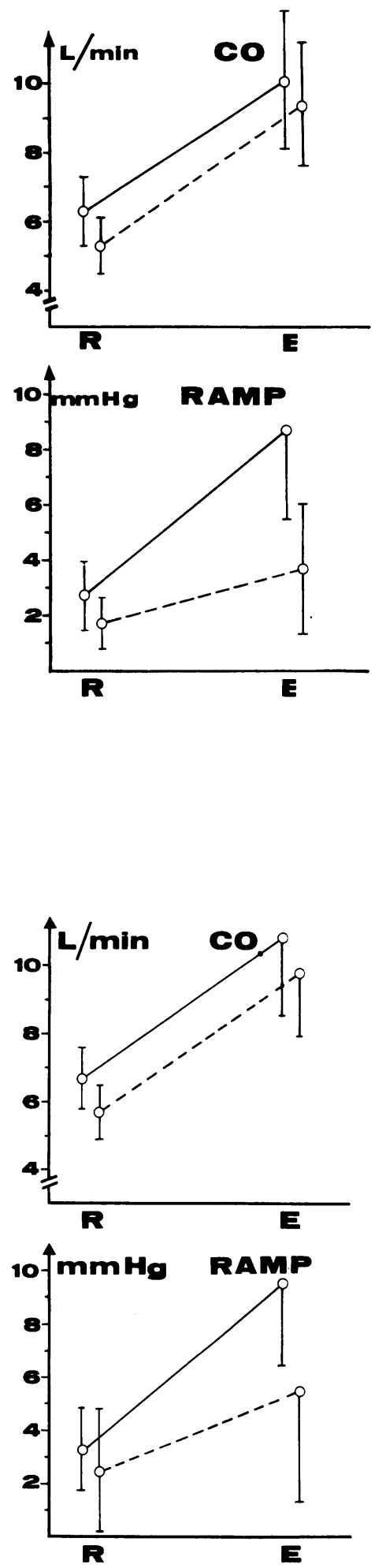
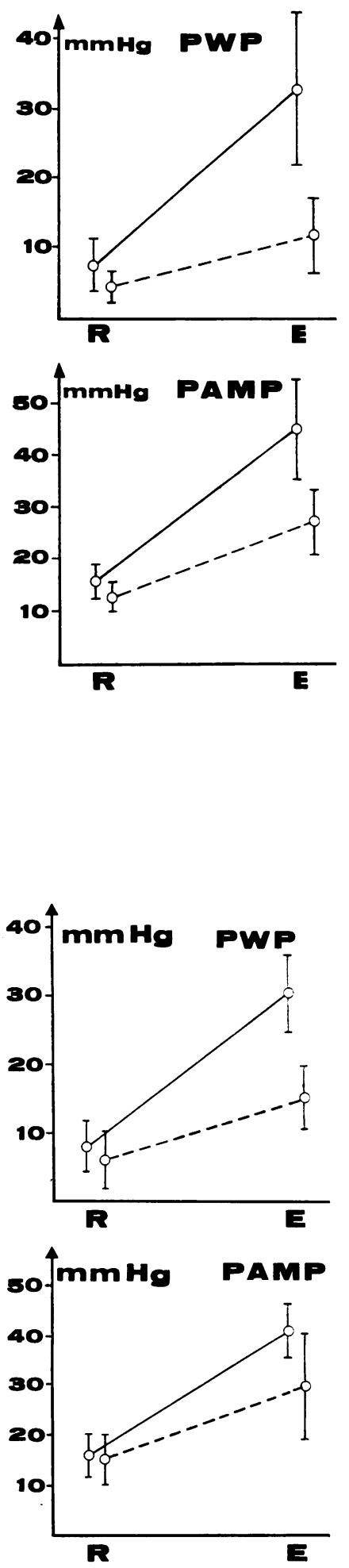

Fig. 1 Mean values of cardiac output (CO), pulmonary artery wedge pressure $(P W P)$, right atrial mean pressure (RAMP), and pulmonary artery mean pressure (PAMP) of 12 patients with coronary artery disease during the control study period (solid lines) and the haemodynamic response to intravenous frusemide (interrupted lines) at rest ( $\mathbf{R})$ and during exercise (E).

Fig. 2 Control values (solid lines) and haemodynamic response to oral frusemide (interrupted lines) in seven patients with coronary artery disease. Same abbreviations as in Fig. 1. 
The occurrence of angina was associated with high left ventricular filling pressures in all but one patient in the pre-frusemide exercise test. Usually the rise of left ventricular filling pressure preceded the beginning of anginal pain. After frusemide administration, filling pressures were lower in all cases throughout the study. When angina was encountered in the post-frusemide exercise test, PWP was higher than in patients without angina, though angina clearly was produced at lower filling pressures compared with the pre-frusemide examination (Fig. 3).

Right ventricular filling pressure, as reflected by right atrial mean pressure (RAMP), also decreased slightly at rest. During exercise, at the same
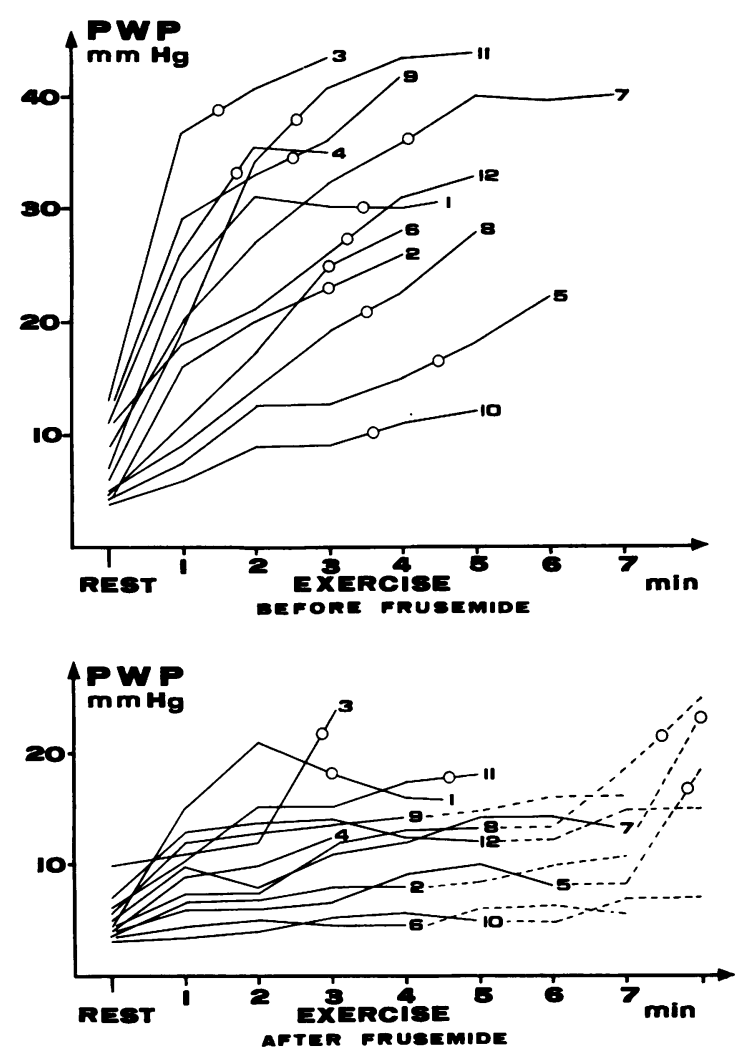

Fig. 3 Individual values of pulmonary artery wedge pressure (PWP) at rest and at one minute intervals during exercise before and after $40 \mathrm{mg}$ intravenous frusemide. The circles indicate the occurrence of angina pectoris. For comparison of data before and after frusemide, the curves of the 12 patients are marked with corresponding numbers. Patients free of symptoms after frusemide at the same exercise duration continued exercising for a further period of time (dotted lines). exercise duration as before frusemide, RAMP in the intravenous group decreased from $8 \cdot 7 \pm 3.3 \mathrm{mmHg}$ to $3.7 \pm 2.4 \mathrm{mmHg}(\mathrm{p}<0.001)$ and in the oral group from $9.5 \pm 3.0 \mathrm{mmHg}$ to $5.6 \pm 4.3 \mathrm{mmHg}$ (p $<0.01$ ).

The decrease in pulmonary artery mean pressure (PAMP) was similar to the PWP reduction after frusemide. The exercise value of PAMP in the intravenous group decreased from $45.2 \pm 9.8 \mathrm{mmHg}$ to $27.3 \pm 6.3 \mathrm{mmHg}(p<0.001)$, and in the oral group from $40.4 \pm 4.7 \mathrm{mmHg}$ to $31.4 \pm 11.3 \mathrm{mmHg}$ ( $p<0.05)$.

Cardiac output at rest after intravenous frusemide fell by 16 per cent $(6.3 \pm 1.01 / \mathrm{min}$ vs. $5 \cdot 3 \pm 0 \cdot 8$ $1 / \mathrm{min}, \mathrm{p}<0.001$ ) and after oral frusemide by 15 per cent $(6.7 \pm 0.91 / \mathrm{min}$ vs. $5.7 \pm 0.81 / \mathrm{min}, \mathrm{p}<0.01)$. The reduction in cardiac output during exercise after frusemide was 7 per cent in the intravenous group $(10.1 \pm 2.01 / \mathrm{min}$ vs. $9.4 \pm 1.81 / \mathrm{min}, \mathrm{p}<0.005)$ and after oral frusemide 10 per cent $(10.9 \pm 2.31 / \mathrm{min}$ vs. $9.8 \pm 1.81 / \mathrm{min}, \mathrm{p}<0.01$ ).

During the control exercise period an increase in the $\mathbf{v}$ wave amplitude was observed in the PWP recordings of seven patients during angina, suggesting mitral regurgitation. These alterations disappeared completely after administration of the drug (Fig. 4a, b).

Heart rate did not change after frusemide, either at rest or during exercise. The average resting heart rate of the 19 patients was $76.3 \pm 13.4 / \mathrm{min}$ during the control period, and $75.9 \pm 13.9 / \mathrm{min}$ after frusemide; the exercise values were $114.7 \pm 18.9$ and $113 \cdot 9 \pm 19 \cdot 1 / \mathrm{min}$, respectively.

Systolic brachial artery pressure was not affected by frusemide (rest: $149.9 \pm 24.0 \mathrm{mmHg}$ vs. 150.8 $\pm 23.4 \mathrm{mmHg}$; exercise: $194.8 \pm 31.1 \mathrm{mmHg}$ vs. $195.9 \pm 32.2 \mathrm{mmHg}$ ). Diastolic blood pressure showed a slight, insignificant increase after frusemide (rest: $92.4 \pm 8.0 \mathrm{mmHg}$ vs. $95.9 \pm 9.1$ $\mathrm{mmHg}$; exercise: $104 \cdot 6 \pm 15 \cdot 4 \mathrm{mmHg}$ vs. $107 \cdot 3 \pm$ $12.3 \mathrm{mmHg}$ ).

(B) ELECTROCARDIOGRAPHIC ABNORMALITIES The extent of electrocardiographic abnormalities is shown in Fig. 5. Maximal ischaemic ST depression during control exercise in the intravenous group was $0.20 \pm 0.07 \mathrm{mV}$, and decreased by 60 per cent to $0.08 \pm 0.04 \mathrm{mV}$ in the post-frusemide exercise test $(p<0.001)$. A similar reduction of ST depression at the same work load and duration occurred after oral administration of frusemide $(0.21 \pm$ $0.08 \mathrm{mV}$ vs. $0.10 \pm 0.08 \mathrm{mV}, \mathrm{p}<0.01$ ).

(C) ANGINA PECTORIS

During the control study period, all patients experienced mild $(n=3)$, moderate $(n=8)$, or severe $(n=8)$ angina at a mean work load of 51 watt 
(range 10 to 110 watt). During exercise after frusemide 10 patients were completely free of chest pain at the same exercise duration. Three patients indicated amelioration of chest pain from "severe" to "mild", three patients from "severe" to "moderate", and two patients from "moderate" to "mild". In one patient the complaints were unchanged. Nine of the ten patients who were completely free of complaints continued exercising at the same level of work load for an average of 3.5 minutes (range 1 to 4.5 minutes). The exercise end-point in these patients was a result of angina (three patients) and exhaustion (six patients).

(D) SERUM POTASSIUM

Serum potassium levels were obtained the day before and several hours after completion of the study. No significant changes could be found after a single intravenous or oral dose of $40 \mathrm{mg}$ frusemide.

There were no side effects or complications during the study.

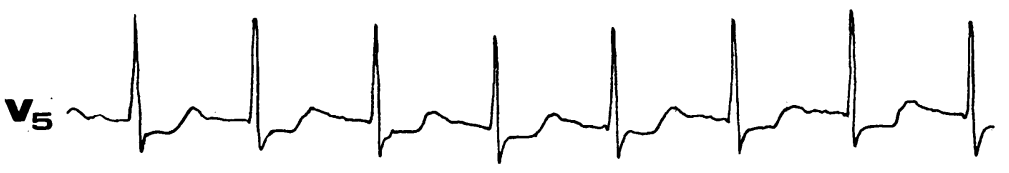

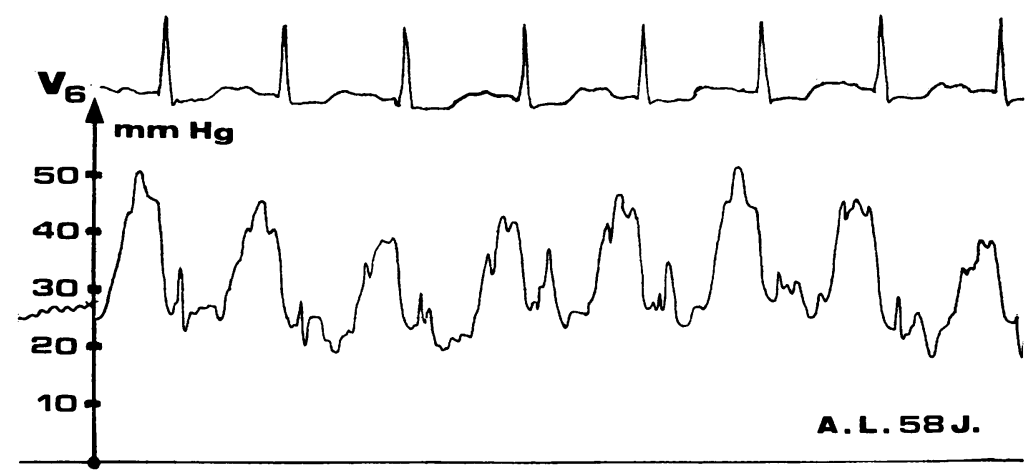

Fig. 4 (a) Upper tracing: recordings of electrocardiographic leads V5 and V6 and simultaneous pulmonary artery wedge pressure $(P W P)$ during severe exerciseinduced angina, showing anomalous $v$, wave amplitudes.

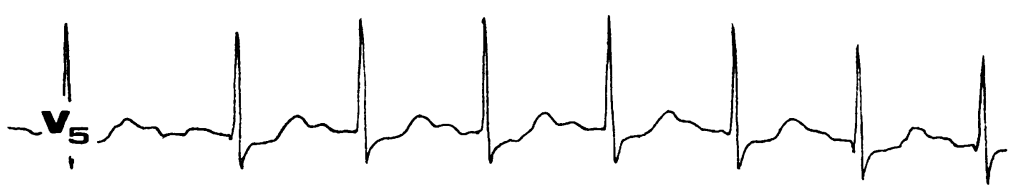

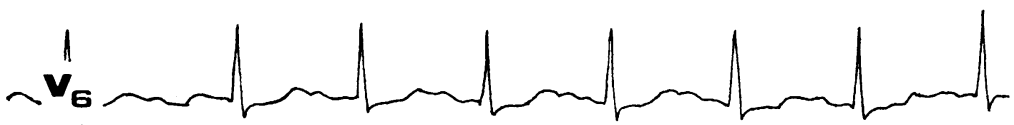

(b) Lower tracing: electrocardiogram and PWP of the same patient at identical work load after intravenous frusemide. There is a striking reduction of the PWP value and a return to normal of the $v$ wave amplitude.

A.L. 58 J.

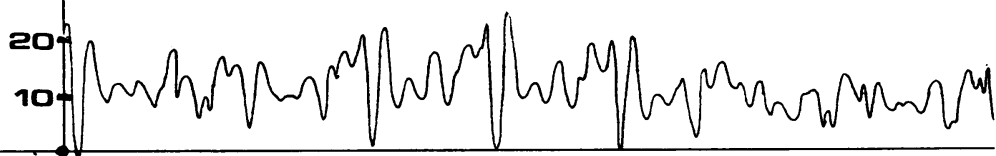




\section{Discussion}

For the purpose of this study it was important not to accept exercise results uncritically. In fact it has been repeatedly shown that the first exercise challenge is usually a learning experience for the patient and that symptoms, pulmonary artery pressures, and other haemodynamic variables may improve during the second exercise period after repeated exercise at the same work load. ${ }^{13}$ Therefore, repeated exercise must be interpreted with caution when studying the effect of pharmacological intervention on haemodynamics. In order to compensate for this phenomenon, an exercise study after any drug intervention should be made during the third rather than during the second exercise test. ${ }^{14}$ This was achieved by an exercise test 30 minutes before the study period at a work load comparable to that of the following pre- and postfrusemide studies. The influence of previous exercise per se on the haemodynamic data during the study period is thus avoided. ${ }^{14}$

The present study shows that the major and most consistent effect of intravenous and oral frusemide is a prompt reduction in right and left ventricular filling pressures at the same level of exercise in patients with angina pectoris. This effect is accompanied in most patients by a reduction or complete suppression of anginal pain during exercise, in conjunction with an improvement in ischaemic ST depression. During angina many investigators have demonstrated a reduction of left ventricular compliance and contractility, resulting in an increase in filling pressure. ${ }^{15-17}$ The increase in filling pressure is not only a consequence of myocardial ischaemia, but results in a further deterioration of oxygen supply in the ischaemic zones, and thus initiates a vicious circle. ${ }^{18}$ These considerations suggest that any intervention aimed at reducing left ventricular filling pressure may be beneficial in the treatment of angina pectoris. It has been shown by Parker et al. ${ }^{19}$ that phlebotomy during an anginal episode is of benefit in ameliorating pain; reduction of left ventricular volumes and pressures was the postulated mode of action. Likewise, the administration of diuretic agents results in a reduction of blood volume and a subsequent decrease in left ventricular dimensions and myocardial fibre length. ${ }^{1-3}$ Since afterload (that is myocardial systolic wall tension) is a function not only of intraventricular systolic pressure but also of ventricular volume, it may be readily appreciated that a diuretic agent that reduces preload may lower afterload by reducing ventricular volume. Furthermore, the action of frusemide is not exclusively related to its diuretic properties. Rather, the immediate haemodynamic effect of the drug is primarily vascular in origin, since pronounced changes in venous capacitance could be shown, indicating a strong venous pooling effect. ${ }^{6} 7$ The haemodynamic effects of frusemide are probably secondary to both fluid depletion and increased venous capacitance.

Our haemodynamic data strongly suggest that the "antianginal" effects of frusemide can be attributed to the unloading action of the drug. Fig. 3 shows that a steep rise in left ventricular filling pressure precedes the occurrence of anginal symptoms in most patients. After administration of frusemide the rise in filling pressures is clearly attenuated and the angina end-point delayed relative to the pre-frusemide end-point. On the other hand, angina in the post-frusemide test, though mitigated, occurred at lower filling pressures than during the control study. One patient (case 10) experienced angina at a very low filling pressure even in the pre-frusemide experiment. These latter results indicate that other mechanisms apart from left ventricular filling conditions are involved in the precipitation and termination of angina pectoris in patients with coronary artery disease.

We have plotted the changes in cardiac output against left ventricular filling pressure after frusemide to provide an approximate assessment of
Fig. 5 The extent of ST segment depression in the electrocardiogram during exercise before and after $40 \mathrm{mg}$ intravenous, and $40 \mathrm{mg}$ oral frusemide, respectively.
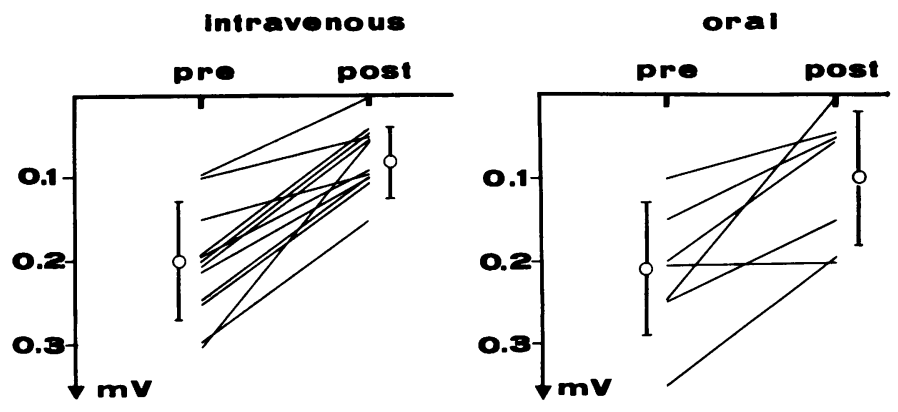
left ventricular function (Fig. 6). The diagram shows only a slight reduction in cardiac output compared with large reductions in pulmonary wedge pressure in all but one patient. In this exceptional case (case 10) initial filling pressure was low in spite of severe angina, and a further decrease in left ventricular filling pressure after frusemide resulted in a substantial fall in cardiac output. Nevertheless, even this patient showed clinical improvement after frusemide. Any increase in cardiac output that might have been expected during exercise because of the improvement in myocardial ischaemia did not result, because of a pronounced reduction in pulmonary wedge pressure, reflecting a large diminution of left ventricular preload.

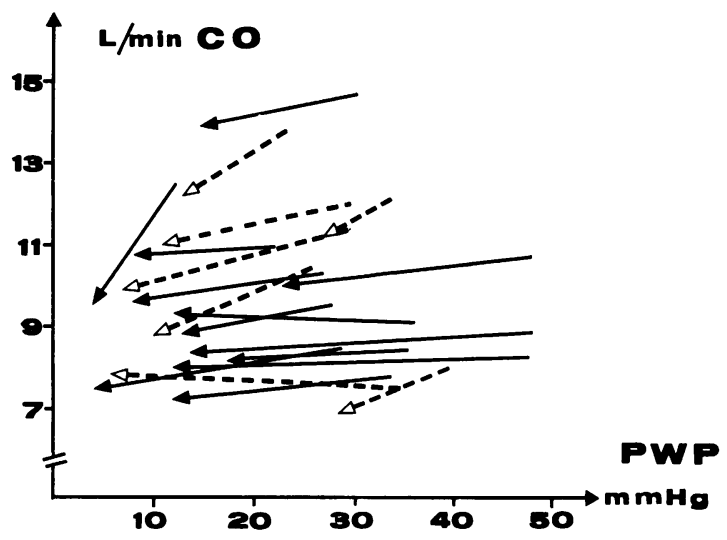

Fig. 6 Changes in cardiac output (CO) in relation to changes in left ventricular filling pressure (PWP) during exercise after $40 \mathrm{mg}$ frusemide in 19 patients with coronary artery disease (solid arrows: intravenous frusemide; interrupted arrows: oral frusemide).

Ischaemic papillary muscle dysfunction resulting in acute mitral regurgitation is probably a common finding in coronary artery disease, at least during exertional angina. ${ }^{20-22}$ The wedge pressure curves in seven patients during exercise were dominated by large $\mathrm{v}$ waves, which we interpreted as suggesting functional mitral regurgitation during severe angina. ${ }^{23}$ Normalisation of the $\mathrm{v}$ wave amplitude after frusemide provides further evidence for the reduction of ischaemia by the drug.

Frusemide-induced changes in cardiac function differ from responses described with other antianginal agents. Data reported from similar studies with glyceryl trinitrate reveal that this drug decreases left ventricular end-diastolic pressure and reduces cardiac output during exercise. It also reduces systemic arterial pressure, and baroreceptor-mediated increases in heart rate tend to have opposite effects on myocardial oxygen consumption. ${ }^{1924}$ Beta blocking agents tend to increase left ventricular filling pressure during exercise in patients with coronary artery disease, as well as in normal subjects, ${ }^{25-27}$ and thus may attenuate the beneficial effect on myocardial oxygen demand. In this study, frusemide improved cardiac performance, as evidenced by a shift to the left of the cardiac output/filling pressure relation, but did not induce changes in systemic blood pressure nor changes in heart rate.

It appears that the antianginal properties of frusemide are the result of reduced left ventricular volume in systole and diastole. This leads to reduced myocardial wall tension and lower myocardial oxygen requirements. Reduction of wall tension during diastole will allow for improved perfusion of the myocardium, especially of the subendocardial layers of the left ventricle. These effects are suggested as being related to the venodilator capacity of frusemide, which is later supplemented by its diuretic action.

Conclusions from these findings should be restricted to the acute symptomatic and haemodynamic response to frusemide, since maintenance diuretic therapy could have substantially different effects in patients with coronary artery disease. Therefore, as long as no controlled clinical study is available, we advocate the additional use of frusemide in patients with angina pectoris only in the presence of concomitant heart failure or hypertension. This concept is compatible with limited clinical observations ${ }^{9}$ that administration of chlorothiazide may be associated with amelioration of the anginal syndrome in hypertensive subjects.

\section{References}

${ }^{1}$ Davidov M, Kakaviatos $\mathrm{N}$, Finnerty FA. Intravenous administration of furosemide in heart failure. $\mathcal{F} A M A$ 1967; 200: 824-9.

'Lal S, Murtagh JG, Pollock AM, Fletcher E, Binnion PF. Acute haemodynamic effects of frusemide in patients with normal and raised left atrial pressures. Br Heart f 1969; 31: 711-7.

${ }^{3}$ Kiely J, Kelly DT, Taylor DR, Pitt B. The role of furosemide in the treatment of left ventricular dysfunction associated with acute myocardial infarction. Circulation 1973; 48: 581-7.

${ }^{4}$ Biagi RW, Bapat BN. Frusemide in acute pulmonary oedema (letter). Lancet 1967; 1: 849.

${ }^{5}$ Bhatia ML, Singh I, Manchanda SC, Khanna PK, Roy SB. Effects of frusemide on pulmonary blood volume. $\mathrm{Br}$ Med f 1969; 2: 551-2. 
${ }^{6}$ Biamino G, Wessel HJ, Schüren KP, Ramdohr B, Nöring J, Schröder R. Hämodynamische Auswirkungen von Furosemid i.v. als Ausdruck eines direkten venodilatatorischen Mechanismus (abstract). $Z$ Kardiol 1974; suppl I: 63: 51 .

'Dikshit K, Vyden JK, Forrester JS, Chatterjee K, Prakash R, Swan HJC. Renal and extra-renal hemodynamic effects of furosemide in congestive heart failure after acute myocardial infarction. $N \mathrm{Engl} \mathcal{F} \mathrm{Med}$ 1973; 288: 1087-90.

${ }^{8}$ Wilkins RW. New drugs for the treatment of hypertension. Ann Intern Med 1959; 50: 1-10.

${ }^{\circ}$ Hollander W, Chobanian AV, Wilkins RW. Relationship between diuretic and antihypertensive effects of chlorothiazide and mercurial diuretics. Circulation 1959; 19: 827-38.

${ }^{10}$ Forsberg SA. Relations between pressure in pulmonary artery, left atrium, and left ventricle with special reference to events at end diastole. Br Heart $\mathcal{F} 1971$; 33: 494-9.

${ }^{11}$ Forrester JS, Granz W, Diamond G, McHugh Th, Chonette DW, Swan HJC. Thermodilution cardiac output determination with a single flow-directed catheter. Am Heart f 1972; 83: 306-11.

${ }^{12}$ Nechwatal W, Eversmann A, Bier P, König E. Determination of cardiac output by means of an automatized thermal dilution technique (in German). Klin Wochenschr 1976; 54: 677-82.

${ }^{13}$ Widimsky J, Berglund E, Malmberg R. Effect of repeated exercise on the lesser circulation. $f A p p l$ Physiol 1963; 18: 983-6.

${ }^{14}$ Spodick DH. First and second versus second and third exercise tests (letter). Circulation 1975; 51: 394.

${ }^{15}$ Wiener L, Dwyer EM Jr, Cox JW. Left ventricular hemodyanics in exercise induced angina pectoris. Circulation 1968; 38: 240-9

${ }^{16}$ Parker JO, Ledwich JR, West RO, Case RB. Reversible cardiac failure during angina pectoris. Circulation 1969; 39: 745-57.

${ }^{17} \mathrm{Cohn}$ PF, Gorlin R. Abnormalities of left ventricular function associated with the anginal state. Circulation 1972; 46: 1065-78.

${ }^{18}$ Arborelius $\mathrm{M} \mathrm{Jr}$, Lecerof $\mathrm{H}$, Malm A, Malmborg, RO. Acute effects of nitroglycerin on haemodynamics of angina pectoris. $\mathrm{Br}$ Heart $\mathcal{F} 1968$; 30: 407-11.

${ }^{19}$ Parker JO, Case RB, Khaja F, Ledwich JR, Armstrong $P W$. The influence of changes in blood volume on angina pectoris: a study of the effect of phlebotomy. Circulation 1970; 41: 593-604.

${ }^{20}$ Brody W, Criley JM. Functional mitral regurgitation (letter). $N$ Engl f Med 1968; 279: 1058.

${ }^{21}$ Burch GE, DePasquale NP, Phillips HJ. The syndrome of papillary muscle dysfunction. Am Heart $\mathcal{F} 1968$; 75: 399-415.

${ }^{22}$ Shelbourne JC, Rubinstein D, Gorlin R. A reappraisal of papillary muscle dysfunction. $A m \mathcal{F}$ Med 1969; 46: 862-71.

${ }^{23}$ Malmborg RO. Physiological signs of incipient cardiac insufficiency in ischemic heart disease. In: Incipient cardiac insufficiency. Symposium of the European Society of Cardiology, Locarno, 1970: 89.

${ }^{24}$ Clausen JP, Trap-Jensen J. Heart rate and arterial blood pressure during exercise in patients with angina pectoris. Effects of training and of nitroglycerin. Circulation 1976; 53: 436-42.

${ }^{25}$ Parker JO, West RO, Di Giorgi S. Hemodynamic effects of propranolol in coronary heart disease. $\mathrm{Am} \mathcal{F}$ Cardiol 1968; 21: 11-19.

${ }^{26}$ Dunér H, Pernow B. Haemodynamic effects of $\beta$ receptor blocking agents and digitalis in ischaemic coronary heart disease with angina pectoris. Acta Med Scand 1973; 194: 517-23.

${ }^{27}$ Nechwatal W, König E, Isbary Greding $\mathrm{H}$. Hemodynamic interaction of propranolol and digitalis in patients with arterial hypertension (in German). $Z$ Kardiol 1977; 66: 572-7.

Requests for reprints to Dr Walter Nechwatal, Division of Cardiology, University of Ulm, Steinhövelstrasse 9, 7900 Ulm, West Germany. 